\title{
A preliminary assessment of the recombinant antigen PLA2 IN THE DIAGNOSIS OF HUMAN DIROFILARIOSIS
}

\author{
VIEIRA C.*, MURO A.*, CORDERO M.** \& SIMÓN F.*
}

\section{Summary :}

Two recombinant antigens (P22U and PLA2), cloned in a L4 Dirofilaria immitis cDNA library, were analyzed by Western-blot and ELISA to investigate their characteristics for the diagnosis of human dirofilariosis. P22U seems related to a Di22 native antigen useful for the diagnosis of pulmonary dirofilariosis, but it is unspecifically recognized by sera from patients with different parasitic and non parasitic pulmonary diseases. PLA2 is not related to Di22 but specifically reacts in Western-Blot and ELISA with sera from patients with subcutaneous dirofilariosis.

KEY WORDS : serologic diagnosis, human dirofilariosis, P22U and PLA2 recombinant $D$. immitis antigens, Di22 native $D$. immitis antigen.
Résumé : Première évaluation de l'ANTIGÈne ReCombinant PLA2 DANS LE DIAGNOSTIC DE LA DIROFILARIOSE HUMAINE

On a analysé avec ELISA et Western blot deux antigènes recombinants (P22U et PLA2), obtenus d'une banque de CDNA de L4 de Dirofilaria immitis, pour définir leurs caractéristiques pour le diagnostic de la dirofilariose humaine. Quoique PU22 paraisse en relation avec Di22, un antigène natif utile pour le diagnostic de la dirofilariose pulmonaire humaine, il est reconnu de manière non spécifique par les sérums de patients souffrant de différentes maladies pulmonaires parasitaires et non parasitaires. PLA2 n'a pas de relation avec Di22, mais pourtant réagit spécifiquement (Western blot et ELISA) avec des sérums de malades souffrant d'une dirofilariose souscutanée.

MOTS CLÉS : diagnostic sérologique, dirofilariose humaine, antigènes recombinants $P 22 U$ et PLA2, D. immitis, antigène natif Di22.
Human dirofilariosis is a zoonosis from warm and temperate zones of the world, mainly due to Dirofilaria immitis and $D$. repens, and causing pulmonary or subcutaneous dirofilariosis. We have recently identified in the adult $D$. immitis native somatic antigen a polypeptide (Di22) specifically recognized by sera from patients with pulmonary dirofilariosis (Perera et al., 1994). As an essential question for the standarization of a serologic test is the source of the antigen, we have analyzed the relationship between Di22 and two recombinant polypeptides with similar molecular weight (pET-19b/PLA2 and pTrcHisB/P22U), cloned in a $D$. immitis $\mathrm{L} 4$ cDNA expression library, and their diagnostic characteristics for the serodiagnosis of human dirofilariosis.

\section{MATERIALS AND METHODS}

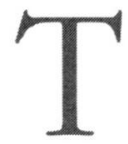

he antigens used were: (1) Two recombinant pET-19b/PLA2 and pTrcHisB/P22U antigens expressed in E. coli. and purified by $\mathrm{Ni}++$ che-

\footnotetext{
* Laboratorio de Parasitología,

** Departamento de Medicina, Universidad de Salamanca, Spain. Correspondence: Prof. Fernando Simón Martín, Lab. Parasitología, Univ. Salamanca, Avda/Campo Charro s/n 37007 Salamanca. SPAIN Tel: 923/294535 - Fax: 923/294515.
}

lation chromatography, kindly provided by Heska Corporation, Fort Collins, Colorado, USA. The calculated molecular weight (MW) of the pET-19b/PLA2 fusion protein is $19 \mathrm{KDa}$, but it runs at $27 \mathrm{KDa}$ on reducing Tris-glycine SDS-PAGE. The calculated MW of the $\mathrm{pTrc}-\mathrm{HisB} / \mathrm{P} 22 \mathrm{U}$ fusion protein is $25 \mathrm{KDa}$, but it runs at $28 \mathrm{KDa}$ on reducing Tris-glycine SDS-PAGE. (2) D. immitis adult somatic antigen (DiSA) obtained as was described in Simón et al. (1991). (3) D. immitis excretory/secretory antigens (DiE/S) obtained as described in Santamaría et al. (1995). (4) L3 D. immitis somatic antigen (SL3) obtained as described in Espinoza et al. (1994), from L3 supplied by the Department of Health and Human Services, National Institutes of Health (Bethesda, Maryland, USA). (5) D. immitis $22 \mathrm{KDa}$ antigen (Di22) obtained from DiSA, by elution from gels (Perera et al., 1994). We employed human and rabbit sera. (1) Human sera from individuals living in an area free of canine dirofilariosis, sera from patients diagnosed as having pulmonary dirofilariosis (Cordero et al., 1990; Cordero et al., 1992), sera from seropositive individuals without pulmonary alterations, and sera from individuals with schistosomosis, fasciolosis, trichinelosis, teniosis, subcutaneous dirofilariosis (diagnosed by histology) and sera from individuals with pulmonary epidermoid carcinoma, microcytic carcinoma, broncheoalveolar carcinoma, benign nodule of unknown origin and tuberculosis. (2) Immune sera 
against Di22, SA, E/S, and SL3 antigens were obtained form rabbits immunized with two doses of each antigen.

The first doses consisted in $200 \mu \mathrm{g}, 400 \mu \mathrm{g}, 200 \mu \mathrm{g}$ and $300 \mu \mathrm{g}$ of each antigen, respectively, with the same volume of Freund Complete Adjuvant. The second doses was constituded by a half of the firsts ones in Freund Incomplete Adjuvant. All the immune sera and their corresponding preimmunes were tested in ELISA against their homologous antigens to corroborate the success of the immunizations. In Western-Blot, the proteins were separated on $12 \%$ gel slabs in a Miniprotean (Bio-Rad Laboratories, Inc. USA) according to the method of Laemli (1970) and transferred to nitrocellulose (Towbin et al., 1979). Enzyme-linked immunoelectrotransfer blotting was performed as described by Tsang et al. (1985). Human sera were used at a dilution of 1:150, and rabbit immune sera at 1:100. Antihuman IgG-peroxidase conjugate was employed at a dilution of 1:500 and anti-rabbit IgG-peroxidase conjugate at 1:3,000. ELISA with PLA2 recombinant antigen was carried out with an antigen concentration of $0,51 \mu \mathrm{g} / \mathrm{ml}$. All sera were tested at 1:50, 1:100, 1:200 and 1:400 dilution. Anti-human IgG-peroxidase conjugate was used at 1:6,000 dilution. The optical density was measured in an Easy Reader EAR 400 FT at $492 \mathrm{~nm}$ (SLT Labinstrument, Austria).

\section{RESULTS AND DISCUSSION}

T he possible relationship between native Di22 and the recombinants PLA2 and P22U is shown in figure 1. All rabbit immune sera including anti-Di22 recognize P22U, although anti-SA with less intensity. On the contrary, none of these immune sera recognized PLA2. The diagnostic interest of PLA2 and P22U for human pulmonary dirofilariosis is shown in figure $2 a$ and $2 b$. P22U is recognized by sera from healthy individuals, sera from individuals diagnosed as having pulmonary dirofilariosis, sera from seropositive individuals without pulmonary alterations, and different types of carcinomas with pulmonary metastasis. On the contrary, most of the sera employed do not recognize PLA2. This polypeptide is recognized only by one serum from an individual with subcutaneous dirofilariosis. According to these results, two other sera from patients diagnosed as having subcutaneous dirofilariosis, and two sera from healthy individuals living in a non-endemic area, were analyzed using ELISA with PLA2 antigen. The results (Fig. 3) show that mean OD's from negative sera are lower than those of the other three sera of patients diagnosed of subcutaneous dirofilariosis, at 1:50 and 1:100 dilutions. Two of them show: DO's three times higher than the

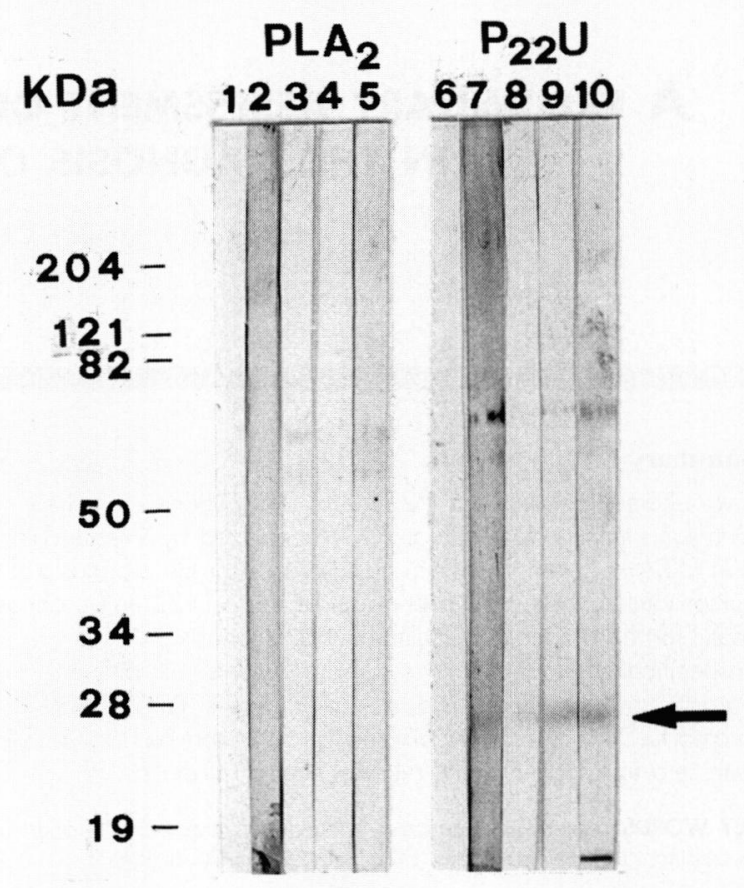

Fig. 1. - Western blot analysis of PLA2 and P22U recombinant antigens with immune sera: 1, 6, Preimmune; 2, 7 Anti-Di22; 3, 8 AntiSA; 4, 9 Anti-E/S; 5, 10 Anti-SL3.

negatives, whereas the other one presents DO twice higher, only at 1:50 and 1:100 dilutions.

In human dirofilariosis, the main problem for the development of a serologic diagnostic test lies in the fact that many more individuals are exposed to the parasite through the bite of an infected mosquito than the ones who really get the disease. The finding of a native antigen (Di22) that is specifically recognized by sera of individuals with pulmonary dirofilariosis (Perera et al., 1994), is an important advance in this sense. In this work we have analyzed the possible diagnostic interest of two recombinant antigens provided by Heska Corporation. The first step was to show the possible relation of these molecules with the native Di22, from an immunological point of view, because we don't have yet their corresponding sequences. The results of the Western-Blot analyses (Fig. 1), seem to indicate that P22U is related, but not the same molecule as Di22. The other tested recombinant protein, PLA2, is not immunologically related to Di22, but its specific recognition in Western-blot by one serum from an individual diagnosed of subcutaneous dirofilariosis, and the subsequent results obtained with ELISA on this and two other sera from patients with similar lesions, makes the possibility worth considering that this molecule could be of interest for the diagnosis of subcutaneous diro- 
a

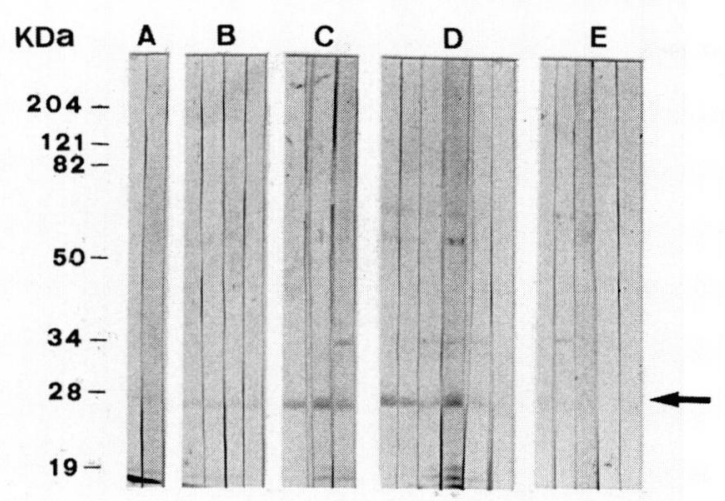

b

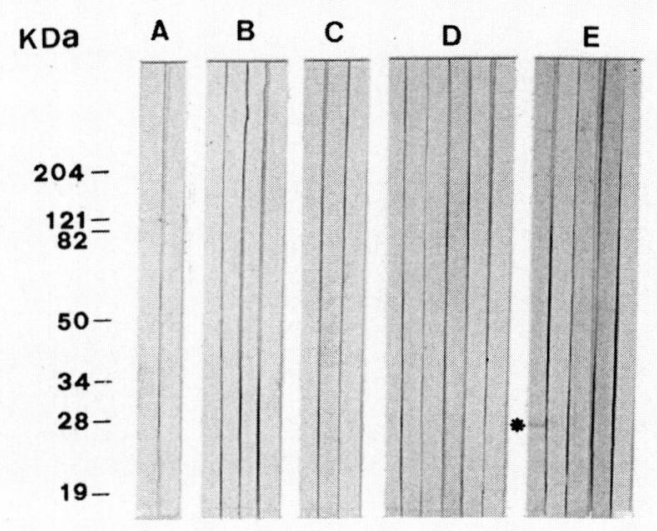

Fig. 2. - Western blot analysis of P22U (a) and PLA2 (b) recombinant antigens with human sera: A. Negative sera; B. Sera from patients diagnosed as having pulmonary dirofilariosis; C. Seropositives without pulmonary alterations; D. Sera from patients with different non-parasitic illnesses: Epidermoid, microcytic and broncheoalveolar carcinoma, tuberculosis and benign pulmonary nodule of unknown origin; E. Sera from patients with different parasitic infections: D. repens, schistosomosis, teniosis, trichinellosis and fasciolosis.

filariosis. In previous studies we have found that sera from individuals with subcutaneous dirofilariasis recognize native proteins in Western-Blot, in a similar molecular range to those of the PLA2 (Santamaría et al., 1995, b).

In conclusion these preliminary results suggest that PLA2 could be suitable as a diagnostic antigen for human subcutaneous dirofilariosis. It is necessary to analyze more sera, to obtain definitive conclusions.

\section{ACKNOWLEDGEMENTS}

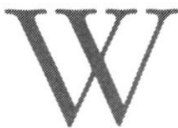

e thank Heska Corporation, Colorado, USA, and Dr. Glenn Frank for providing the recombinant polypeptides. We also thank the Department of Health and Human Service,

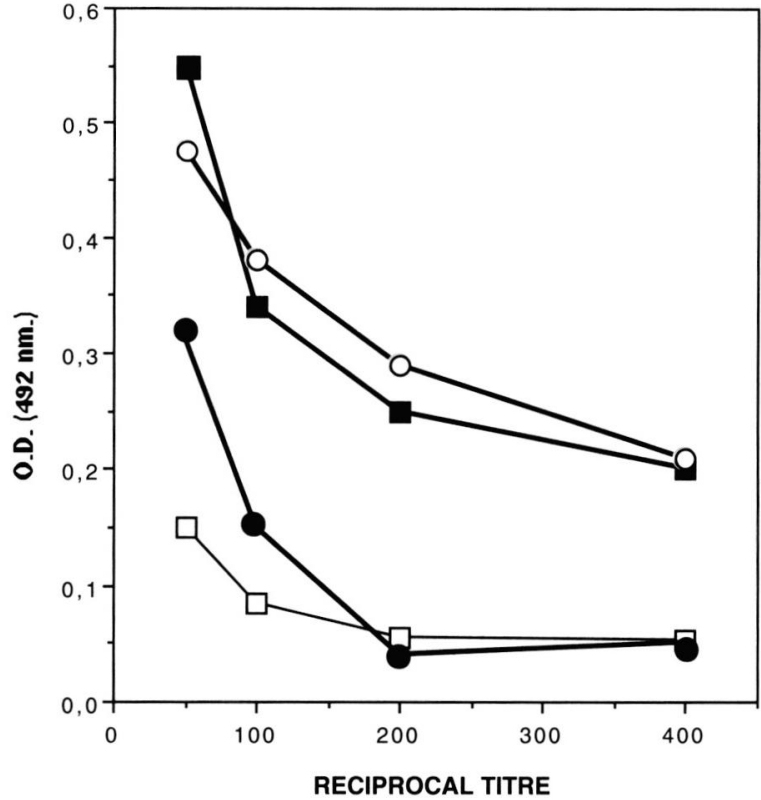

Fig. 3. - ELISA analysis with PLA2 recombinant antigen of 3 sera diagnosed as having subcutaneous dirofilariosis by histology $(\bullet \circ \bullet)$, and 2 negative sera from individuals living in an area free of canine dirofilariosis. The mean OD's of these two sera ( $\square$ ) appear in the figure.

National Institutes of Health (Bethesda, Maryland, USA) for providing $\mathrm{L} 3$ of $D$. immitis. This work has been supported by Grant $n^{\circ} 2 \mathrm{SA} / 49 / 94$ of the Consejería de Cultura y Turismo, Junta de Castilla y León, Spain.

\section{REFERENCES}

Cordero M., Muñoz M.R., Muro A. \& Simon F. Transient solitary pulmonary nodule caused by Dirofilaria immitis. European Respiratory Journal, 1990, 3, 1070-1071.

Cordero M., Muñoz M.A., Muro A., Simon F. \& Perera M.L. Small calcified nodule: an undescribed radiologic manifestation of human pulmonary dirofilariosis. Journal of infectious diseases, 1992, 165, 398-399.

Espinoza E., Muro A., Lorente F., Cordero M. \& Simon F. AntiDirofilaria immitis IgE: Seroepidemiology and seasonal evolution in an exposed human population. Tropical Medicine and parasitology, 1993, 44, 172-176.

LAEMmLi U.K. Cleavage of structural proteins during the assembly of the head bacteriophage T4. Nature, 1970, 227, 680-685.

Maizels R.M., Gregory W.F., Kwan-Lim G.-E., SElkirk M.E. Filarial surface antigens: the major 29 kilodalton glycoprotein and a novel 17-200 kilodalton complex from adult Brugia malayi parasites. Molecular and Biochemical Parasitology, 1989, 32, 213-228. 
Perera L., Muro A., Cordero M., Villar E. \& Simon F. Identification, purification and evaluation of a $22 \mathrm{KDa}$ Dirofilaria immitis antigen for the immunodiagnosis of human pulmonary dirofilariosis. Tropical Medicine and Parasitology, 1994, 45, 249-252.

Santamaria B., Cordero M., Muro A. \& Simon F. Evaluation of Dirofilaria immitis excretory/secretory products for seroepidemiological studies on human dirofilariosis. Parasite, 1995, 2, 269-273. (a)

Santamaria B., Di Sacco B., Muro A., Genchi C., Simon F. \& Cordero M. Serological diagnosis of subcutaneous dirofilariosis. Clinical and Experimental Dermatology, 1995, 20, 19-21. (b)

Simon F., Muro A., Cordero M. \& Martin J. A seroepidemiologic survey of human dirofilariosis in western Spain. Tropical Medicine and Parasitology, 1991, 42, 106-108.

Towbin H., Staechelin T. \& Gordon J. Electrophoretic transfer of proteins from polyacrilamide gels to nitrocellulose sheets: procedure and some applications. Procidings of the National Academy of Sciences USA, 1979, 76, 4350-4354.

Reçu le 14 novembre 1996 Accepté le 14 mars 1997 